\title{
Comparative Study of Tensile Behaviour for Layered Polymeric Composite Materials
}

\begin{abstract}
MARINELA MARINESCU1', LARISA BUTU1*, CLAUDIA BORDA ${ }^{1}$, DELICIA ARSENE ${ }^{1}$, MIHAI BUTU ${ }^{1}$
Politehnica University of Bucharest, 313 Splaiul Independentei, 060042, Bucharest, Romania

In this paper we present a comparative study on tensile failure behavior of polymer stiffened composite shell structures, using infrared thermography and finite element analysis through the ABAQUS 6.13 program. The establishment of the distortion of some rectangular shaped specimens was followed. In these specimens a hole with a diameter of $15 \mathrm{~mm}$ was applied centrally. By means of infrared thermography, was studied experimentally the variation of the deformations over time, depending on the stress force and the evolution of the thermal field in the crack area. Simulation models of failure behavior have been performed, which have been validated by experimental results.
\end{abstract}

Keywords: stiffened shell polymeric composites, infrared thermography, finite element simulations

Composite materials are increasingly used in areas other than aeronautics, automobiles or the shipping industry, such as: buildings and civil infrastructure, sports equipment, medical equipment and prosthetic devices, etc.

The widespread use of composite materials has led to the development of new technologies for their manufacture as well as new techniques of high efficiency investigation and repair, in order to anticipate the behavior of composite materials and structures made of these materials, under various types of demands and under different environmental conditions.

Obtaining composite materials to meet the mechanical properties of operating conditions, increasingly diversified, is a permanent challenge for researchers.

In order to evaluate the behavior of a composite material during operation, field specialists can use a wide range of CAD / CAE programs to provide solutions to problems encountered in exploiting them. Due to their structural complexity polymer composite shell material cannot be mathematically modeled just like classical materials. Modeling of fiber reinforced shell composites is very difficult, but also very useful, as results can be very close to reality, related to the behavior of each lamina of the laminate $[1,2]$. With these models, fiber and matrix fracture, delamination, deformations, etc. that appear in the shell composite can be highlighted.

A finite element simulation software that offers very close results to experimental results is ABAQUS. It allows the mechanical analysis of fiber-reinforced laminated composite materials with the following advantages: simplicity of concepts, generality and the ease of analysis, pre and postprocessing facilities.

Using this program the mathematical model for the specimens tested from the composite polymeric material epoxy resin - glass fiber $E$. The purpose of this analysis was to determine the location of the fracture and the size of the composite deformations during the stresses.

\section{Theoretical considerations}

Tensile breaking resistance is considered one of the most important properties. The use of reinforcing fibers increases the modulus of elasticity. The unidirectional arrangement of the fibers in the matrix also leads to an increased tensile resistance of the composite $[3,11]$.
In the experiment, the loading force was applied parallel to reinforcement fibers (fig. 1). To determine the mechanical characteristics of the layered composites, the following approximations were used: there is perfect adhesion between the fibers and the matrix; the fiber and the matrix have different elastic modulus but the Poisson ratio value is the same; both, the fiber and the matrix, have a linear elastic behavior [4, 12].

We consider that the layered composite is in a state of equilibrium; then the force $P$ to be loaded to the composite as a whole will be balanced by an equal and opposite force of the fiber, $P_{f}$ and the matrix one, $P_{m^{\prime}}$ this means:

$$
P=P_{m}+P_{f}
$$
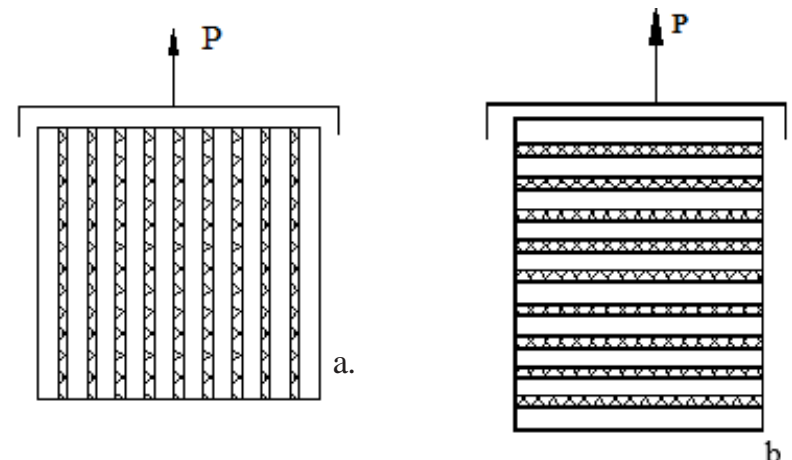

Fig. 1. The direction of the loading force: $a$ - parallel to the fibers; $\mathrm{b}$ - perpendicular to the direction of reinforcement fibers

If it is note the cross section of the composite with $\mathrm{A}$, the cross section of the fiber with $A_{f}$ and that of the matrix with $A_{m}$, then the strain state in the composite is given by the sum of the fiber and matrix tensile values, multiplied by the value of the cross section:

$$
\begin{aligned}
& \sigma \cdot A=\sigma_{m} \cdot A_{m}+\sigma_{f} A_{f} \\
& \sigma=\sigma_{m} \frac{A_{m}}{A}+\sigma_{f} \frac{A_{f}}{A}
\end{aligned}
$$

Because the fibers have the same length inside the composite, the $A_{m} / A$ and $A / A$ ratios can be replaced by their volumetric fractions, respectively $V_{\text {p }}$ and $V_{f}$ If $V_{f}=f$ and because $V_{m}+V_{f}=1$ then $\mathrm{Vm}=(1-f)$ and the fiber tension $\sigma$ is given by:

$$
\sigma=\sigma_{m}(1-f)+\sigma_{f} f
$$


Considering Hoke's law, $\sigma=E \varepsilon$, where $E$ is the modulus of elasticity and $\varepsilon$ the deformation, equation (1) becomes:

or:

$$
E \varepsilon=(1-f) E_{m} \varepsilon+f E_{f} \varepsilon
$$

$$
E=(1-f) E_{m}+f E_{f}
$$

If the matrix and the fibers have different elastic properties, they will obtain different deformations, the deformation of the composite materials being the average of the deformation volume in each material.

If the force is applied perpendicular to the fibers (fig. 1.b), the total elongation $\delta$ is the sum of the fiber elongations $\delta_{f}$ and the matrix $\delta_{m^{\prime}}$ then:

or:

$$
\delta=\delta_{m}+\delta_{f}
$$

$$
\varepsilon=\varepsilon_{m}(1-f)+\varepsilon_{f} f
$$

Using Hooke's law and introducing the modulus of elasticity in to equation (8), is determined the modulus of elasticity perpendicular to the fiber:

$$
\begin{gathered}
\frac{\sigma}{E}=\frac{\sigma}{E_{m}}(1-f)+\frac{\sigma}{E_{f}} f \\
E=\left(\frac{E_{f} E_{m}}{(1-f) E_{f}+f E_{m}}\right)
\end{gathered}
$$

The rigidity of the composite material, measured perpendicularly to the fibers, increases much less than the rigidity measured in the direction parallel to the fibers, if the volum fraction of the fibers increases.

Calculation of the tensile strength of composites is quite complicated because primarily they are anisotropic and irregular material and secondly due to irregular breakage due to structural variations in both the fiber and the matrix, defects of the internal voids type and not least because of the concentration of strenghts.

When the load is applied parallel to the orientation direction of the fibers, both the fibers and the matrix acquires the same deformations, distinguishing two situations: the matrix breaks first or the fibers break first.

In the case of the composite material tested, the matrix is the one that broke first when the composite deformation reached the maximum deformation of the matrix.
The entire load is then transferred to the fibers, which occupy a certain volume in the composite. The breaking strength $\sigma_{R R}$ in the composite can be calculated when the matrix is nearly broken with the relationship:

$$
\sigma_{R R}=f \sigma_{f}^{\prime}+(1-f) \sigma_{m R R}
$$

where $\sigma_{f}^{\prime}$ is the tensile strength that occurs in the fiber when the composite breaks, so:

$$
\sigma_{R R}=f E_{f} \varepsilon_{m}+(1-f) E_{m} \varepsilon_{m}
$$

The force $\mathrm{P}$ applied to the composite is given by:

$$
P=\sigma A=\left\lfloor f E_{f} \varepsilon_{m}+(1-f) E_{m} \varepsilon_{m}\right\rfloor A
$$

When the matrix breaks, the fibers that take up the load will have the resistance at $\sigma_{\text {fiber }}$ given by the relationship:

$$
\sigma_{\text {fiss }}=\frac{P}{f A}=\frac{\left\lfloor f E_{f} \varepsilon_{m}+(1-f) E_{m} \varepsilon_{m}\right\rfloor A}{f A}=E_{f} \varepsilon_{m}+\frac{1-f}{f} \sigma_{m s=}
$$

where: $\sigma_{m R R}$ is the tensile strenght in the broken matrix.

Once the matrix breaks, the fiber tension increases to its value $(1 / f-1) \sigma_{m}$. If the increased strenght is not sufficient to break the fibers, then the tensile strength of the composite $\sigma_{R R}$ is:

$$
\sigma_{R R}=f \sigma_{f R R}
$$

where $\sigma_{f R R}$ is the limited tensile strength of the fibers.

\section{Experimental part \\ Tensile test}

The experiments were performed on a number of 5 specimens made of the same composite polymeric material with the following dimensions: $150 \times 100 \times 4[\mathrm{~mm}]$ (fig. 2.a). The layered composite is a glass fiber-reinforced epoxy resin, reinforced with glass fiber $\mathrm{E}$; this material has eight laminas with a of thicknesses of $0.5 \mathrm{~mm}$ and the next architecture $[0 / \pm 45 / 90]_{\text {s. }}$.

In each specimen a $15 \mathrm{~mm}$ diameter hole was centrally located (fig. 2.b). The aim was to establish and then simulate the running behavior of a piece, in which there are such holes, and subjected to different loads $[7,8]$.

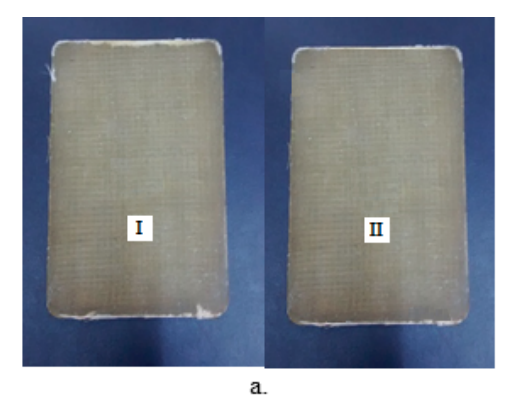

Fig. 3. Harnessing the layered composite specimen in the machine's trains to be tested for the tensile test: $a$. before testing; $b$. during the test were applied

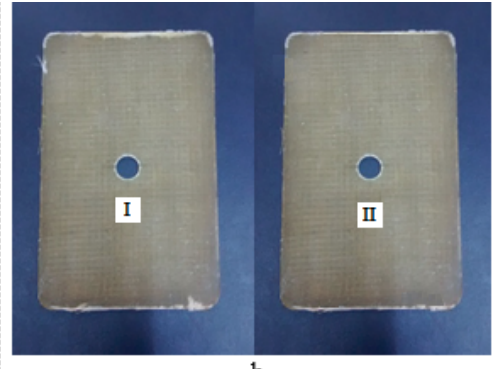

Fig. 2. Layered composite specimen: a. before drilling; b. after drilling. 
With the ABAQUS soft, layered composite structure response simulations were performed regarding different load types corresponding to several practical applications.

The specimen were tested on the traction testing machine, the force being applied at a constant speed of $2 \mathrm{~mm} / \mathrm{min}$ (fig. 3).

\section{Investigating the deformation process by infrared} thermography

To visualize and investigate the area of initiation and propagation of composite material breakage, a ThermaCAM SC640 infrared camera was used during sample traction stresses.

The high-definition SC640 features a large $640 \times 480$ pixel focal plane array for the most advanced infrared temperature measurement applications that demand thermal measurements of plastics, injection molding and mechanical testing.

As a tool for capturing and recording thermal patterns in real time, the SC640 helps us visualize and quantify these patterns in the devices create and events monitor providing an instant, accurate way to evaluate thermal performance.

To establish a technology review by infrared thermography in the various activities, it is necessary to browse the following steps: defining the system of examination parameters; defining the areas of the object to be detected; selecting the scheme examination and a heating variant; the thermography plant selection; the thermography parameters setting: the examination geometrical parameters, recording time, method of recording and viewing results; the facility thermography calibration; the real time examination; the obtained results analysis.

\section{The experimental stand}

The experimental stand consisted of: the universal tensile testing machine 60tf hydraulic actioned, computer with dedicated software attached to the traction testing machine, ThermaCAM SC640 infrared camera, ThermaCam Researcher SR2 software computer for taking and interpreting the results. 4.

The schematic diagram of the stand is shown in figure

The infrared camera contains a radiometer with a matrix detector, consisting of a microbolometer netw ork without a separate cooling system.

The examination parameters were set as follows: examination scheme: passive, recording frequency 7.5 sequences / sec, Rain 900 color palette, temperature range: $0 \div 500^{\circ} \mathrm{C}$, subdomain (automatically set by camera) 26 $\div 46.5^{\circ} \mathrm{C}$, ambient temperature: $26^{\circ} \mathrm{C}$, humidity content $50 \%$, emissivity of 0.9 , the distance from the camera to specimen of $1 \mathrm{~m}$.

\section{Results and discussions}

The research was aimed at reflecting the traction behavior of the epoxy-glass fiber composite material, in

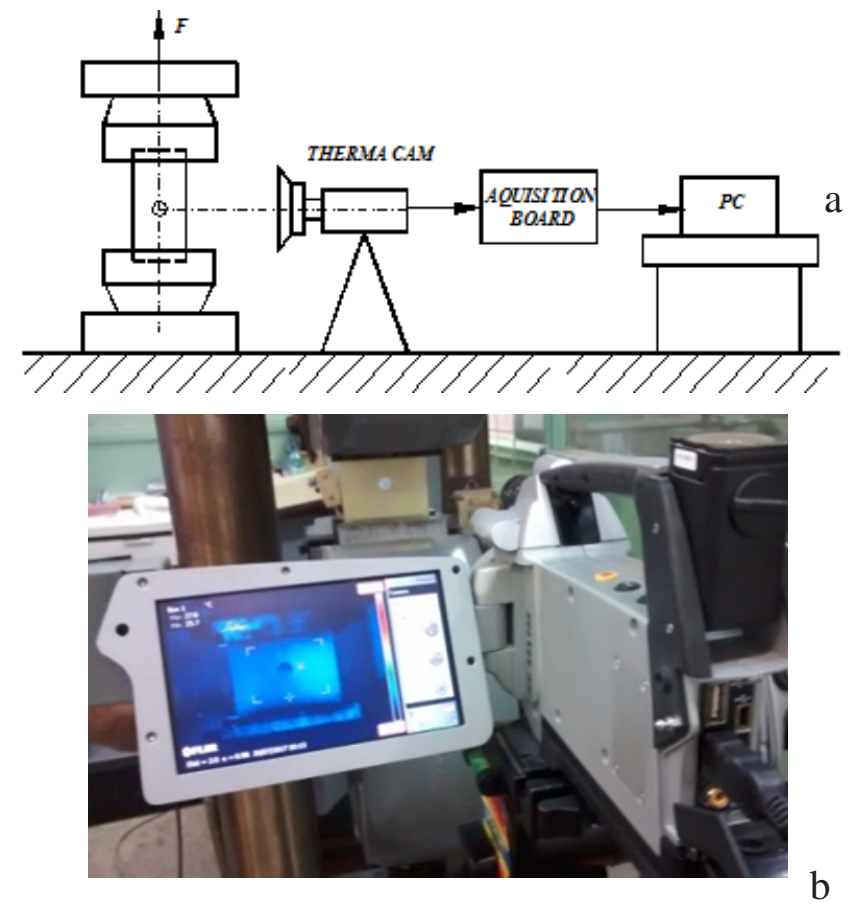

Fig. 4. The experimental stand: a. block diagram; b. overwiew

which a stress concentrator has materialized in the form of a centrally located circular hole.

Tests were performed at the ambient temperature. The measured parameters were: tensile strength, displacement, time and temperature dynamics inside the composite. For all 5 specimens the force was applied at a rate of $2 \mathrm{~mm} / \mathrm{min}$. Specimens images after the test are shown in figure 5.

Following the experimental tests, it has been observed that the mod of propagation of the cracks in the layered polymeric composite material, provided with a centrally located circular stress concentrator, corresponds to the theoretical studies in the field. The initiation of cracks during mechanical stresses occurred perpendicularly to the direction of the loading force, having as a starting point the median line of the circular hole. From figure 5 it can be seen that the matrix is the one that failed the first, when the applied force exceeded about 1500kgf. Since the matrix failed, the entire load was then transferred to the fibers (samples III and V in fig. 5). Because the matrix and the fibers have different elastic properties, they have obtained different deformations (samples I-V in fig. 5).

\section{Variation of displacements depending on applied force}

From the experimentally measured values were plotted the variations of the deformations according to the applied force. A linear time variation consistent with the deformation theory in the literature was found $[13,15,16$, 17]. The dependence of sample elongation on the force applied are shown in figure 6 .

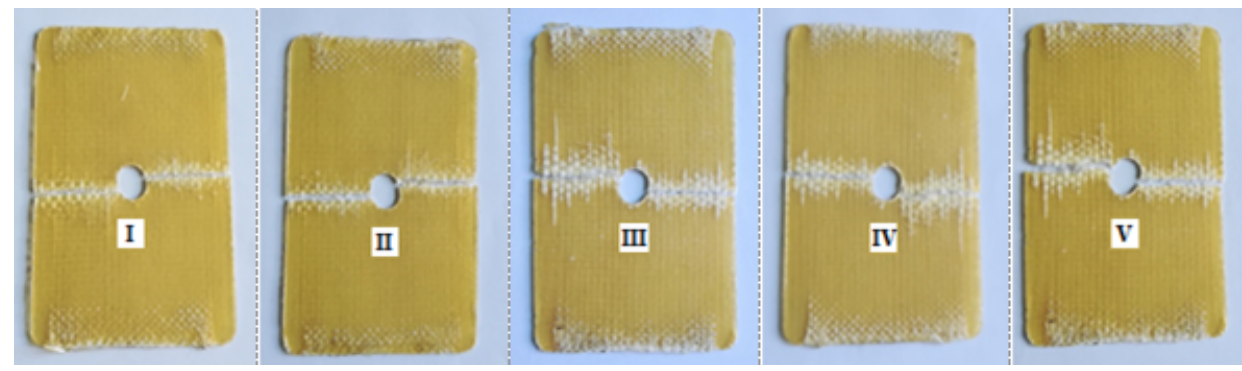

Fig. 5. Specimens after the tensile test. 


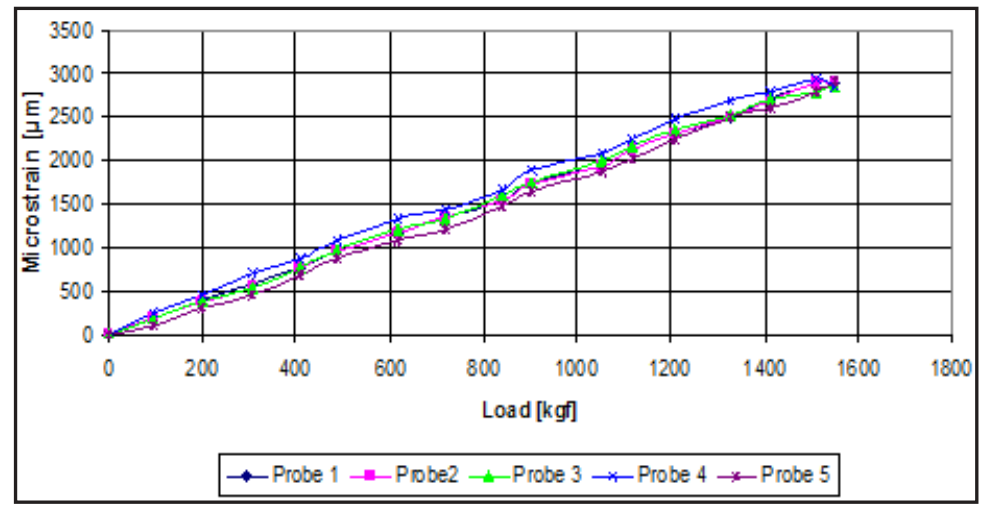

Fig. 6. Variation of specimens displacements according to the applied tensile strength

Thermography investigation of the progressive damage process

The advantages of the thermography testing are that not only the subsurface defects can be made visible, but also, according to the delay of the response, their depths can be estimated.

In the case of active thermography inspection with an infrared camera, the spatial and temporal distribution of the surface temperature is recorded. As cracks, defects and delamination disturb the heat flow, evaluating the infrared images can reveal hidden failures [6].

For understanding the possibilities and importance of non-destructive thermography analysis with respect to the possibility of doing quick and keen area failure detection, several images of damaged specimens were compared and explained with the load-time curves, visual detection and thermography analysis results $[6,9,10]$.

After the analysis of the acquired thermography images, it was found that: the start of the crack occurred in the immediate near of the hole, symmetrical and perpendicular to the direction of application of the loading force.

Figures $7-9$ show the evolution of the thermal field during the tensile test of the sample I.
An ascending evolution of samples temperature was observed in the crack area, from ambient temperature to a maximum of about $49^{\circ} \mathrm{C}$, reached at the time of breaking the composite matrix.

The data acquired with ThermaCam Researcher SR2 software allowed plotting of temperature variation graphs during crack propagation for the 5 specimens tested (fig. 10). The maximum infrared camera temperature recorded at the damage time was in the range $46 \div 49^{\circ} \mathrm{C}$.

One of the advantages of the thermography analysis method is to precisely determine the point of initiation of material damage under the action of a given loading. As can be seen in figure 10, for the tested specimens, the exceeding of the temperature range of $28-30^{\circ} \mathrm{C}$ coincides with the initiation of the crack. The unexpectedly rise in temperature inside the composite signifies the crack of the matrix, identified on the graph by increasing the slope of the curves.

The presence of defects, in fact, induces a localized variation in its temperature distribution and, then, the measured values of the surface temperature can be used
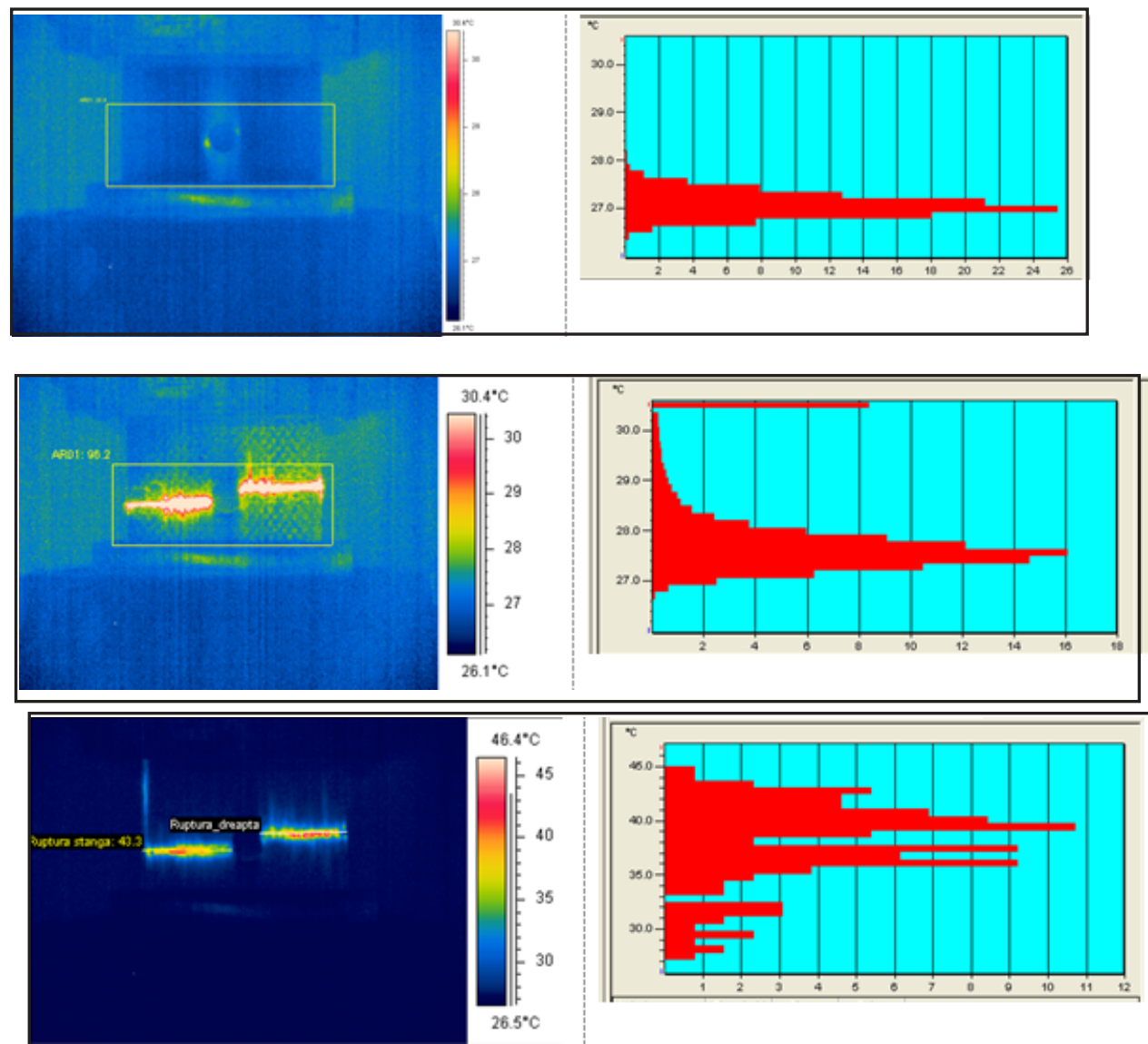

Fig. 7. The thermal field at the time of microcrack initiation in specimen $\mathrm{l}$, at $\mathrm{t}=72 \mathrm{~s}$.

Fig. 8. The thermal field during crack propagation in I at $\mathrm{t}=82 \mathrm{~s}$.

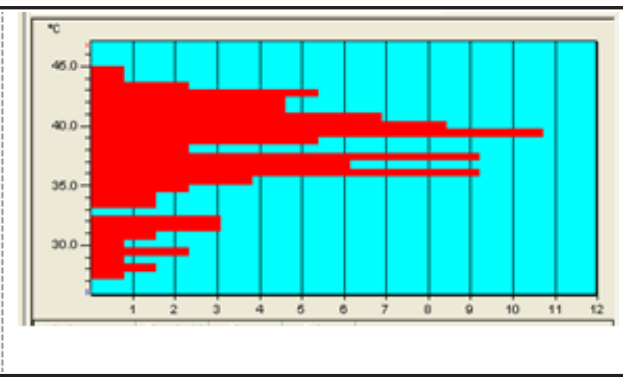

Fig. 9. Thermal field at the damage time of the layers in sample I at time $\mathrm{t}=93 \mathrm{~s}$. 


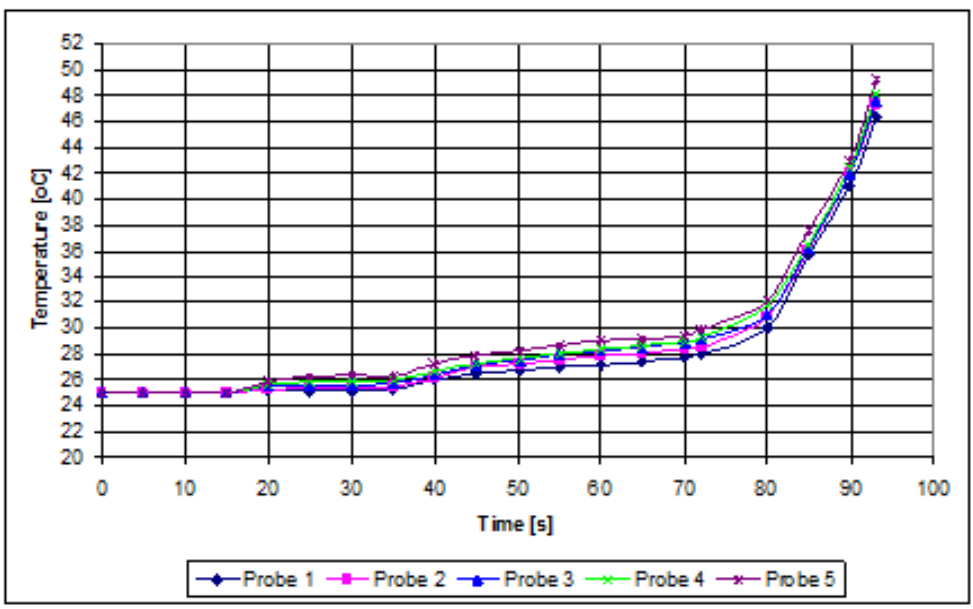

Fig. 10. Temperature variation in the layered composite material specimens, during the damage propagation

to localize and evaluate the dimensions and the evolution of defects.

Another advantage is the possibility of quantifying the time to the total damage of the material.

This method of investigating the damage process completes well with the design and simulation of the behavior of layered composite materials through the ABAQUS software.

\section{Modeling and simulation of the layered composite behavior} at the tensile loading

The damage analysis of the structure and the prediction of the behavior of the layered composite under the action of some stresses requires the establishment of the compressive, tensile or shear stresses, as well as the knowledge of elastic properties, such as the elasticity coefficient and the Poisson ratio, the stiffness coefficient. These properties are influenced by several variables,

namely: the type of fibers, the type of reinforcement, the volume of fibers, the processing methods.

The evaluation of composite material behavior, under the action of a product-like request, was performed using the ABAQUS finite element analysis software [5]. Modeling layered composite and in the aim of the efficiency, it was taken into account that the shape and dimensions of the model influence the precision and analysis time.

Composites analysis is challenging because it requires: orthotropic material stiffness terms (E's, G's, Nu's); lamina (ply) thickness; fiber orientation-draping; understanding of stacking sequence implications; orthotropic strengths; understanding of numerous potential modes of failure and the various failure theories.

The finite element analysis of the tested specimens began with the construction of the model defining its geometry (fig. 11.a). In the Cartesian coordinate system, a

\begin{tabular}{|c|l|l|}
\hline Nr. crt & Properties & Value \\
\hline 1. & Modulus of elasticity & $\mathrm{E}_{1}=49 \times 10^{8}\left[\mathrm{Kg} \cdot \mathrm{m}^{-1} \mathrm{~s}^{-2}\right]$ \\
& & $\mathrm{E}_{2}=12 \times 10^{8}\left[\mathrm{Kg} \cdot \mathrm{m}^{-1} \mathrm{~s}^{-2}\right]$ \\
& $\mathrm{E}_{3}=12 \times 10^{8}\left[\mathrm{Kg} \cdot \mathrm{m}^{-1} \mathrm{~s}^{-2}\right]$ \\
\hline 2. & Shearing module & $\mathrm{G}_{12}=61 \times 10^{8}\left[\mathrm{Kg} \cdot \mathrm{m}^{-1} \mathrm{~s}^{-2}\right]$ \\
& & $\mathrm{G}_{23}=50 \times 10^{8}\left[\mathrm{Kg} \cdot \mathrm{m}^{-1} \mathrm{~s}^{-2}\right]$ \\
& & $\mathrm{G}_{13}=61 \times 10^{8}\left[\mathrm{Kg} \cdot \mathrm{m}^{-1} \mathrm{~s}^{-2}\right]$ \\
\hline 3. & Young modulus & $\mathrm{E}=10 \times 10^{6}\left[\mathrm{Kg} \cdot \mathrm{m}^{-1} \mathrm{~s}^{-2}\right]$ \\
\hline 4. & Poisson ratio & $v_{12}=0.25$ \\
& & $v_{23}=0.32$ \\
\hline 5. & Maximimum Tensile strenghst & $v_{13}=0.25$ \\
\hline 6. & & $\sigma_{11}=104 \times 10^{3}\left[\mathrm{Kg} \cdot \mathrm{m}^{-1} \mathrm{~s}^{-2}\right]$ \\
& & $\sigma_{21}=8.15 \times 10^{2}\left[\mathrm{Kg} \cdot \mathrm{m}^{-1} \mathrm{~s}^{-2}\right]$ \\
& & $\sigma_{31}=8.15 \times 10^{2}\left[\mathrm{Kg} \cdot \mathrm{m}^{-1} \mathrm{~s}^{-2}\right]$ \\
\hline 7. & Maximum Compressive strenghts & $\sigma_{1 \mathrm{c}}=50 \times 10^{3}\left[\mathrm{Kg} \cdot \mathrm{m}^{-1} \mathrm{~s}^{-2}\right]$ \\
\hline 8. & Transverse shear strenght & $\sigma_{2 \mathrm{c}}=8 \times 10^{3}\left[\mathrm{Kg} \cdot \mathrm{m}^{-1} \mathrm{~s}^{-2}\right]$ \\
& & $\sigma_{3 \mathrm{c}}=8 \times 10^{3}\left[\mathrm{Kg} \cdot \mathrm{m}^{-1} \mathrm{~s}^{-2}\right]$ \\
\hline & & $\tau_{12}=2.3 \times 10^{3}\left[\mathrm{Kg} \cdot \mathrm{m}^{-1} \mathrm{~g}^{-2}\right]$ \\
\hline & & $\mathrm{K}_{11}=2.25 \times 10^{-3}\left[\mathrm{Kg} \cdot \mathrm{m}^{-1} \mathrm{~s}^{-2}\right]$ \\
& & $\mathrm{K}_{12}=32300\left[\mathrm{Kg} \cdot \mathrm{m}^{-1} \mathrm{~s}^{-2}\right]$ \\
& & \\
\hline
\end{tabular}

Table 1

PROPERTIES OF THE ANALYZED COMPOSITE MATERIAL

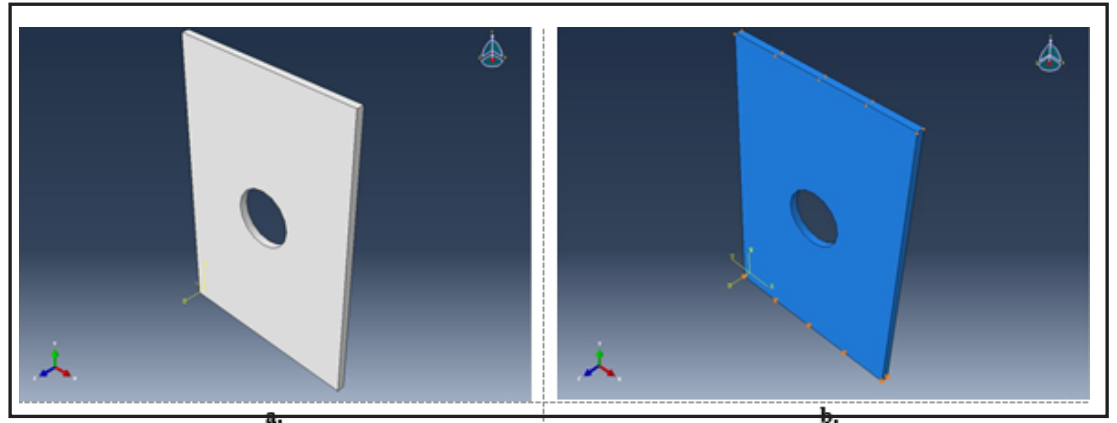

Fig. 11. Design of composite geometry and application of loads 
plate was created with the following dimensions: width (on $X$ axis) $=0.1 \mathrm{~m}$; length (on $Y$ axis) $=0.15 \mathrm{~m}$; thickness (on $Z$ axis) $=0.004 \mathrm{~m}$, center is a hole with a radius of $0.015 \mathrm{~m}$. The composite shell consists of wet epoxy resin reinforced with wet $\mathrm{E}$ glass fibers volume fraction about $60 \%$. All layers of the composite were modeled as linear elastic orthotropic materials. The layers are assumed to be isotropic in the crosswise direction [14]. The properties of the composite material required for 3D analysis are shown in table 1. The properties of the composite material used for mathematical modeling have been established by comparison with those found in the literature [19-23] for composites with the same matrix and the same succession of layers and topology. The layers have a thickness of $0.5 \mathrm{~mm}$ and the following topology: [0/ $\pm 45 /$ $90] \mathrm{s}$, resulting in a total thickness of $4 \mathrm{~mm}$.

The layered composite material requirements presented in figure $11 \mathrm{~b}$ are: one-end embedding and controlled loading that produces a $0.8 \%$ deformation of the plate width $(0.8 \times 150=1.2 \mathrm{~mm}=0.0012 \mathrm{~m})$.

The meshing of the model was performed so that the resulting finite elements would constitute adjacent subdomains that could fully reconstruct the original body to be analyzed. In a first step, the meshing process leads to the transformation of the analysis domain into a set of finite elements. The size of the finite elements directly influences the convergence of the solutions. The size of the smaller elements was chosen to predict a better final solution. For meshing, the SC8R element, shown in figure 12 , was used.

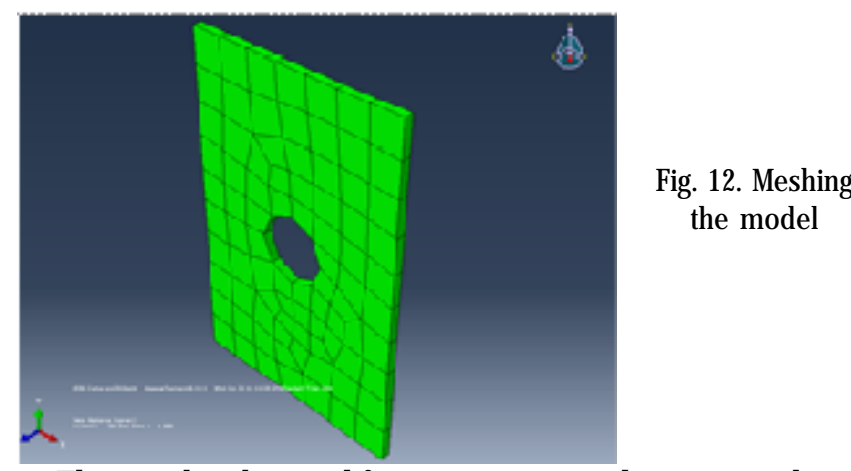

The results obtained from progressive damage analysis show that the displacement value is the maximum in the proximity of the hole perpendicular to the direction of application of the loading force. The captured image (fig. 13) indicates the appearance of some cracks having the horizontal axis propagation direction. The variation field of deformations resulting from the run of the program allowed to highlight the maximum displacements of: $2.76 \mathrm{~mm}$ on the $Y$ axis (fig. 13). This value is comparable to the average of $2.88 \mathrm{~mm}$ resulting from the experimental tests performed on the 5 samples, which validates the mathematical model achieved, with a $4.2 \%$ error.

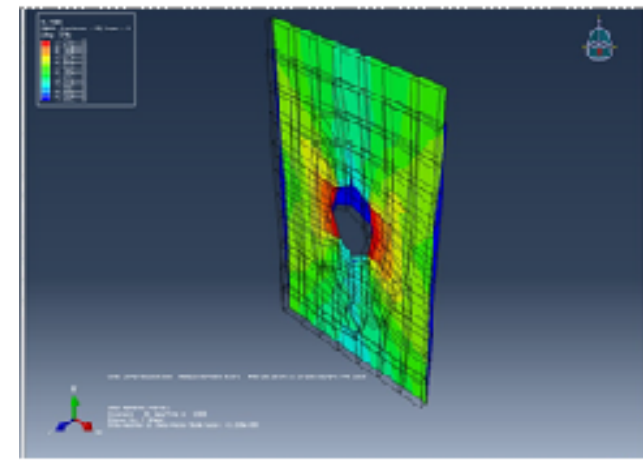

Fig. 13. Model response under the load
It has also been found that the simulation indicates the same point of initiation of the crack as with the experimental results acquired with the thermography camera.

\section{Conclusions}

The comparative analysis revealed a similarity between the experimental tests, the mathematical simulation and the thermal analysis on the way of placing and propagating of the cracks in the layered polymeric composite material, provided with a centrally located circular tension concentrator. The existence of this type of concentrator, in rectangular plate composite products, makes it possible to accurately locate the possible point of initiation of cracks during operational applications. The two methods used, the finite element modeling and the thermal analysis, proved to be two viable solutions in estimating the behavior of these materials.

The infrared thermography technique allows to highlight the thermal flow distribution anomalies caused by the presence of a discontinuity in the composite material. The characterization of an infrared thermography product is based on the correlation between the thermal radiation emission and the different characteristics of the product under examination. The study showed that the appearance of overheating, signaled by the thermal radiation absorbed by the composite material during the load application, indicates the possibility of a starting of the crack, which may lead to the failure of the part. It is thus possible to approximate the time to the total rupture of the material.

The proposed mathematical model, built with the ABAQUS program, simulates the exploitation behavior of the analyzed composite material, which proved to be very close to the results of the experimental tests. This makes it useful in predicting the lifetime of multiple complex configurations, made from various composite polymeric composite materials subjected to different types of stresses.

Simultaneous monitoring of internal deformation and breakage by cracking of the composite matrix is very important for the purpose of assessing structural integrity. Instant crack and internal deformation of the composite structure can be detected by infrared thermography. The initial deformation in the damage process of the composite structure was instantly determined when the temperature acquired with the ThermaCAM SC640 camera suddenly increased.

Research on multidirectional composites opens the way for the use of this method for monitoring structural integrity during composite working.

\section{References}

1.HADAR, A., Structuri din compozitestratificate, Editura Academiei si Editura AGIR, Bucuresti, 2002.

2.BOLCU, D., STANESCU, M.M., CIUCA, I., DUMITRU, S., SAVA, M., The Non-uniformity from the Composite Materials Reinforced with Fiber Glass Fabric, Mat. Plast., 51, no. 1, 2014, p. 97-100.

3.TANAKA, M., and others - Influence of non-uniform fiber arrangement on tensile fracture behavior of unidirectional fiber/epoxy model composites, Composite Interface, 12(3-4), 2005, pg. 365-378.

4.AGARWAL, B.D., BROUTMAN, L.J., Analysis and performance of fiber composite, Brookfield, Connecticut, 06804, U.S.A, 1990, pg. 2072014.

5.ABAQUS Theory Manual - Analysis of Composite Materials with ABAQUS, HKS (2006).

6.MAIER A., SCHMIDT R., OSWALD-TRANTA B., SCHLEDJ EWSKIR. Non-Destructive Thermography Analysis of Impact Damage on LargeScale CFRP Automotive Parts, Materials 2014, 7, pg. 413-429; ISSN 19961944. 
7.EMERY, T. R., DULIEU-BARTON, J. M., Thermoelastic Stress Analysis of damage mechanisms in composite materials, Composites Part A: Applied Science and Manufacturing, 41, 2010, pg. 1729-1742.

8.GREENE, R., PATTERSON, E., ROWLANDS, R., Thermoelastic Stress Analysis. In: Springer Handbook of Experimental Solid Mechanics, ed. W. N. Sharpe, J r., (2008), pg. 743-768.

9.LIBONATI, F., VERGANI, L.,Damage assessment of composite materials by means of thermographic analyses, Composites Part B: Engineering, 50, 2013, pg. 82- 90.

10.MALDAGUE, $X$.- Theory and practice of infrared technology for nondestructive testing, Wiley, 2001.

11.GHEORGHIU, H., HADAR, A., CONSTANTIN, N., Analiza structurilor din material izotrope si anizotrope, Editura Printech, Bucuresti, 1998. 12.SIERAKOWSKI, J.R., VINSON, R.L., The Behavior of Structures Composed of Composite Materials, Kluwer Academic Publishers, 2002.

13.REDDY, J., N.,Mechanics of Laminated Composite Plates and Shells. Theory and Analysis, CRC Press LLC, 2003.

14.REIFSNIDER, K., OGIHIRA, S., Characterization of nonlinear behavior in woven composite laminates, Applied Composite Materials, vol. 9, pp. 249-263, 2002.

15.PUCK, A., Analysis of Failure in Fiber Polymer Laminates, Springer, 2008.
16.KULAKOV, Y., M, TARNOPOLSKII, V., L., Tests Methods for Composites, Mechanics of Composite, vol. 37, pp. 431-448, 2001. 17.J AMAL OMIDI, M., MAHMOOD M. SHOKRIEH, M., Tension behavior of unidirectional glass/epoxy composites, Composite Structures, vol. 88, pp. 595-601, 2009.

18.BRIA, V., ROMAN, I., UNGUREANU, V., CIRCIUMARU, A., BIRSAN, I.G., Thermal Properties of Particulate Epoxy Composites, Proceedings of the 3rd Symposium With International Participation Durability and Reliability of Mechanical Systems, pp. 319-321, 2010.

19.GRANT, P., ROUSSEAU C.Q., Composite Structures: Theory and practice, ASTM Stock Number: STP 1383; Printed in Philladelphia, P.A., pp. 220-305, oct. 2000.

20.ADAMS, D., CARLSSON, L., PIPES, R., B., Experimental characterization of advanced composite materials, CRC Press, taylor and Francis Group, ISSN 13:978-1-4200-3200-4, pp 11-34, 2002.

$21 . * * *$, Composite materials handbook. Polymer matrix composites materials, MIL - HDBK-17-2F, Volume 2 of 5, pp. 457 - 487, 2002.

22.J ORDAN, J. L., FOLEY, J. R., SIVIOUR, C. R., Mechanical properties of Epon 826/DEA epoxy. Mechanics of Time-Dependent Materials, 12, pp. 249-272, 2008.

23.SONG, B., CASEM., D., KIMBERLEY, J., Dynamic behavior of materials, vol 1, Proceedings of the 2013 Annual Conference on Experimental and Applied Mechanics, SEM, Springer, N.Y, U.S.A., pp 73 - 107, 2013.

Manuscript received: 15.05 .2018 